\title{
Article
}

\section{Breast Milk for Preterm Multiples: More Proteins, Less Lactose}

\author{
Marco Congiu ${ }^{1}$, Alessandra Reali ${ }^{1}$, Federica Deidda ${ }^{2}$, Angelica Dessi ${ }^{1}$, Flaminia Bardanzellu ${ }^{1, \star}$ and Vassilios Fanos ${ }^{1}$ \\ ${ }^{1}$ Neonatal Intensive Care Unit, AOU and University of Cagliari, Monserrato, Italy and ${ }^{2} 3 \mathrm{~A}$ Arborea Laboratories, Arborea Milk S.COOP.AGR.P.A., Arborea, Italy
}

\begin{abstract}
Exclusive breastfeeding is currently recommended until at least 6 months of postnatal age, due to maternal breast milk (BM) unique composition and beneficial properties. In fact, BM modifies itself according to gestational age (GA) at birth, adapting its composition to neonatal requests during lactation. Multiple births represent about $3 \%$ of the whole pregnancies; such neonates result more vulnerable than full-term newborns, due to lower GA and birth weight (BW) and the higher incidence of perinatal complications. Although an adequate nutrition is fundamental for twins and other multiples, studies on this topic are lacking. We collected and analyzed BM from mothers of 19 twins and 5 triplets showing GA $<33$ weeks and $\mathrm{BW}<1500 \mathrm{~g}$, comparing it to a control group of 28 preterm singletons. As a result, at GA $\leq 28$ weeks, we observed that protein content is higher in BM for multiples (1.53 vs. $1.29 \mathrm{~g}$ per $100 \mathrm{ml}$ ), lactose concentration is greater in BM for singletons (6.72 vs. $6.34 \mathrm{~g}$ per $100 \mathrm{ml}$ ) and GA results the most relevant factor influencing BM protein composition. BM for multiples results higher in proteins and lower in lactose, if compared with singleton's samples; this could promote and sustain growth and organ development in this vulnerable category. BM from multiples shows a trophic and immunologic role, since these neonates often show lower GA and BW instead of singletons. These findings could help in optimizing nutritional strategies and improving BM individualized fortification.
\end{abstract}

Keywords: Breastfeeding; singletons; twins; triplets; quadruplets; multiples; preterm newborns; Neonatal Intensive Care Unit

(Received 16 May 2019; accepted 19 June 2019)

Maternal breast milk (BM) represents the most suitable source for the newborn's nutrition. Thus, exclusive breastfeeding is recommended until at least 6 months of age. BM is able to fulfill neonatal needs, promoting a satisfying growth and adequate maturation (ESPGAN Committee on Nutrition, 1982). Such precious biofluid shows a complex composition that varies according to newborn development, adapting itself to its nutritional requests during the early stages of development. BM is composed by macroand micronutrients, immunological and trophic components, maternal-derived cells and, finally, a particular microbiome (Andreas et al., 2015).

Early maternal mammary secretion during the first phase after delivery is represented by colostrum, whose macroscopic and microscopic features significantly differ from mature milk (MM). Colostrum is rich in secretory immunoglobulins, lactoferrin, leukocytes and growth factors, but if compared with MM, it contains less lactose; this suggests a prominent immunological and trophic function, rather than a nutritive role (Ballard \& Morrow, 2013).

MM contains an average of $3.4 \mathrm{~g}$ of lipids per 100 milliliters $(\mathrm{ml})$; in colostrum, lipid average value is lower at $1.8 \mathrm{~g}$ per 100 $\mathrm{ml}$. Protein content ranges from $2 \mathrm{~g}$ per $100 \mathrm{ml}$ during the first lactation phase to $1 \mathrm{~g}$ per $100 \mathrm{ml}$ in MM. Among carbohydrates, lactose is the most represented; it increases from early lactation (average content about $5.6 \mathrm{~g}$ per $100 \mathrm{ml}$ ) to MM production (mean value $6.5 \mathrm{~g}$ per $100 \mathrm{ml}$; Gidrewicz \& Fenton, 2014).

Author for correspondence: Flaminia Bardanzellu, Email: bardanzellu.flaminia@ virgilio.it

Cite this article: Congiu M, Reali A, Deidda F, Dessì A, Bardanzellu F, and Fanos V. (2019) Breast Milk for Preterm Multiples: More Proteins, Less Lactose. Twin Research and Human Genetics 22: 265-271, https://doi.org/10.1017/thg.2019.42
The BM of each mother modifies its composition depending on the specific needs of her newborn, underlining the importance of the mother-neonate dyad. In detail, BM characteristics vary according to gestational age (GA) at birth: BM in mothers delivering preterm differs from samples belonging to mothers of fullterm neonates (Bardanzellu et al., 2017). According to a recent meta-analysis, colostrum from mothers delivering preterm contains about $49 \mathrm{Kcal}$ per $100 \mathrm{ml}$, with an average lipid content of $2.2 \mathrm{~g}$ per $100 \mathrm{ml}$, a protein average value of $2.7 \mathrm{~g}$ per $100 \mathrm{ml}$ and lactose that reaches an average value of $5.1 \mathrm{~g}$ per $100 \mathrm{ml}$. In MM for preterm newborns, these average values are, respectively, $73 \mathrm{Kcal}$ per $100 \mathrm{ml}, 3.3 \mathrm{~g}$ per $100 \mathrm{ml}, 1.1 \mathrm{~g}$ per $100 \mathrm{ml}$ and $6.2 \mathrm{~g}$ per $100 \mathrm{ml}$ (Gidrewicz \& Fenton, 2014).

However, even if $\mathrm{BM}$ produced by mothers of preterm babies is richer in macronutrients and energy content, in some conditions it is not sufficient to satisfy their nutritional needs. Therefore, BM for such a vulnerable category of newborns should be fortified to increase its protein fraction and energy content (Su, 2014).

Current evidence regarding BM composition derives from studies on lactating women delivering a singleton. Until now, in the scientific literature, characteristics of BM samples deriving from mothers of multiples (twins, triplets or other multiples) have not been adequately investigated and clarified. To the best of our knowledge, the only study on this topic was performed by Saint et al. (1986); however, this older study was conducted on a small sample of lactating women (seven mothers of twins and one mother of triplets).

The lack of studies in this field is quite inappropriate, taking into account that multiple births occur in about $3 \%$ of all 
pregnancies (Machin, 2009). As reported in the literature, multiples' mean GA and birth weight (BW) are lower than singletons. In detail, mean GA is 29.5 weeks for quadruplets, 31.9 weeks for triplets, 35.3 weeks for twins and 38.7 weeks for singletons; mean BW results are $1291 \mathrm{~g}$ for quadruplets, $1660 \mathrm{~g}$ for triplets, $2336 \mathrm{~g}$ for twins and $3296 \mathrm{~g}$ for singletons (American College of Obstetricians and Gynaecologists, 2016; Martin et al., 2011). Moreover, about $54 \%$ of twins undergo preterm delivery (GA $<37$ weeks); of these, $32 \%<35$ weeks and $9 \%<32$ weeks (Collins \& Shennan, 2016). In conclusion, in the perinatal phase, multiples are more vulnerable than singletons.

Adequate neonatal nutrition is crucial, especially in the most vulnerable categories of newborns. Thus, in our opinion, analyzing BM collected by mothers delivering multiple fetuses could be useful to optimize nutritional strategies and improve BM fortification. From this perspective, such a study aims to clarify an ongoing debate to evaluate BM features in a population of extremely preterm and very low BW multiples, to confirm whether a multiple pregnancy represents an independent factor influencing BM composition in lactating mothers.

Samples from mothers delivering multiples were compared with BM collected from singletons' mothers during different lactation stages to detect BM modifications over time. Finally, we investigated the role of some additional factors that potentially influence BM in multiple pregnancies.

\section{Methods}

\section{Study Population}

The BM analysis shown in this article was included in an ongoing individualized fortification program undertaken at our Neonatal Intensive Care Unit (NICU; Reali et al., 2010, 2015), aimed at optimization of the samples intended for each neonate according to his or her particular needs. Therefore, it is not an experimental study but rather a welfare protocol, in which BM analysis is performed to improve its composition, which is often inadequate for preterm newborns.

Subjects of this study were enrolled from preterm newborns admitted to the NICU of the University of Cagliari, whose hospital is located in Monserrato. They were selected from preterm neonates with a GA $<33$ weeks, from multiple pregnancies (twins, triplets or multiples), between September 2011 and November 2017. Multiples were eligible if at least one of the neonates showed a BW $<1500$ g. According to these inclusion criteria, our final sample was composed of 19 pairs of twins and 5 sets of triplets; among the triplets, one pregnancy underwent an embryo reduction and the number of fetuses was reduced to one.

Thus, the total number of newborns was 51 (25 males and 26 females), with a mean GA of $28.92 \pm 2.5$ weeks and a mean BW of $1076.62 \pm 318.45 \mathrm{~g}$.

We used a control group composed of 28 preterm singletons ( 13 males and 15 females), GA $\leq 28$ weeks (mean $26.29 \pm 1.49$ weeks) and mean BW $816.25 \pm 168.64 \mathrm{~g}$, enrolled between July 2005 and May 2012 in our NICU. In Table 1, we report complete data regarding enrolled patients.

\section{Sample Collection}

BM sampling started between the 1st and the 9th week of postnatal life and terminated between the 15th and 20th week; a total pool of 103 samples was collected from 19 pairs of twins and 5 sets of triplets with an average of $4.29 \pm 3.46$ samples for each twin pair or
Table 1. Principal characteristics of enrolled patients

\begin{tabular}{lcc}
\hline Neonatal characteristics & Multiples $\left(n=24^{\mathrm{a}}\right)$ & Singletons $(n=28)$ \\
\hline M/F & $25 / 26$ & $13 / 15$ \\
\hline GA $(w)$ & $28.92 \pm 2.5$ & $26.29 \pm 1.49$ \\
& $(24-33)$ & $(23-28)$ \\
\hline BW & $1076.62 \pm 318.45$ & $816.25 \pm 168.64$ \\
& $(510-1820)$ & $(520-1250)$ \\
\hline AGA/SGA & $43 / 8$ & $27 / 1$ \\
\hline
\end{tabular}

Note: $\mathrm{GA}=$ gestational age, $\mathrm{w}=$ weeks, $\mathrm{BW}=$ birth weight, $\mathrm{AGA}=$ appropriate for $\mathrm{GA}, \mathrm{SGA}=$ small for $\mathrm{GA}$.

Mean values are expressed as mean \pm standard deviation (SD).

${ }^{\mathrm{a}} 19$ twins and 5 triplets (one of these had undergone embryo reduction to a single fetus).

triplet set. BM samples were obtained each week and analyzed to detect changes during lactation. In some cases, sampling was not undertaken until the end, as highlighted in Figure 1.

\section{Sample Analysis}

Each sample, constituted by $10 \mathrm{ml}$ of BM, was evaluated within 24-36 h after the weekly collection and underwent a quantitative and qualitative analysis to attest lipid, protein and lactose concentrations. A mid-infrared analyzer (MilkoScan FT2) was used. During sampling, storage and transport, operators followed sterility and cold chain rules. To estimate the whole energy content, the quantity of each single macronutrient detected was multiplied for its nutritional reference value $(4 \mathrm{Kcal}$ per $\mathrm{g}$ for carbohydrates and proteins, $9 \mathrm{Kcal}$ per $\mathrm{g}$ for lipids); finally, all of these values were summed.

\section{Statistical Analysis}

Results obtained underwent a statistical analysis. In the comparison between the two samples, we used Student's $t$ test to detect a significant difference; thus, the results with a $p$ value $\leq .05$ were considered significant.

To establish a correlation between lactation time and/or the correct GA and the variation of considered parameters, we measured the correlation coefficient $(r)$. Finally, to attest the significance of such results, these were submitted to the Student's $t$ test, as explained above.

\section{Results}

Among the $103 \mathrm{BM}$ samples collected from the multiples group, the average lipid content was $3.78 \pm 0.54 \mathrm{~g}$ per $100 \mathrm{ml}$, the average protein value was $1.55 \pm 0.23 \mathrm{~g}$ per $100 \mathrm{ml}$, lactose concentration was equal to $6.34 \pm 0.3 \mathrm{~g}$ per $100 \mathrm{ml}$ and the average energy value was $65.59 \pm 5.26 \mathrm{Kcal}$ per $100 \mathrm{ml}$ (Table 2).

Moreover, we performed a weekly evaluation. We analyzed 84 BM samples obtained between the 2nd and 10th week. The results suggest a significant inverse correlation between the weeks of postnatal life and BM protein content $(r=-.46 ; p<.0001)$. Regarding other components, no significant modification was detected over time. Results are shown in Figure 2.

To obtain a better comparison among multiples' BM samples, the time window was subsequently reduced to the period between the third and sixth week of GA, in which the results of the samples were more complete. One twin pair from the twins' group was excluded due to the absence of data regarding the BM received. 
Table 2. BM composition in the multiples population

\begin{tabular}{|c|c|}
\hline Multiples' BM characteristics & \\
\hline Lipids (g/100 ml) & $3.78 \pm 0.54$ \\
\hline Proteins (g/100 ml) & $1.55 \pm 0.23$ \\
\hline Lactose (g/100 ml) & $6.34 \pm 0.3$ \\
\hline Energy value (Kcal/100 ml) & $65.59 \pm 5.26$ \\
\hline
\end{tabular}

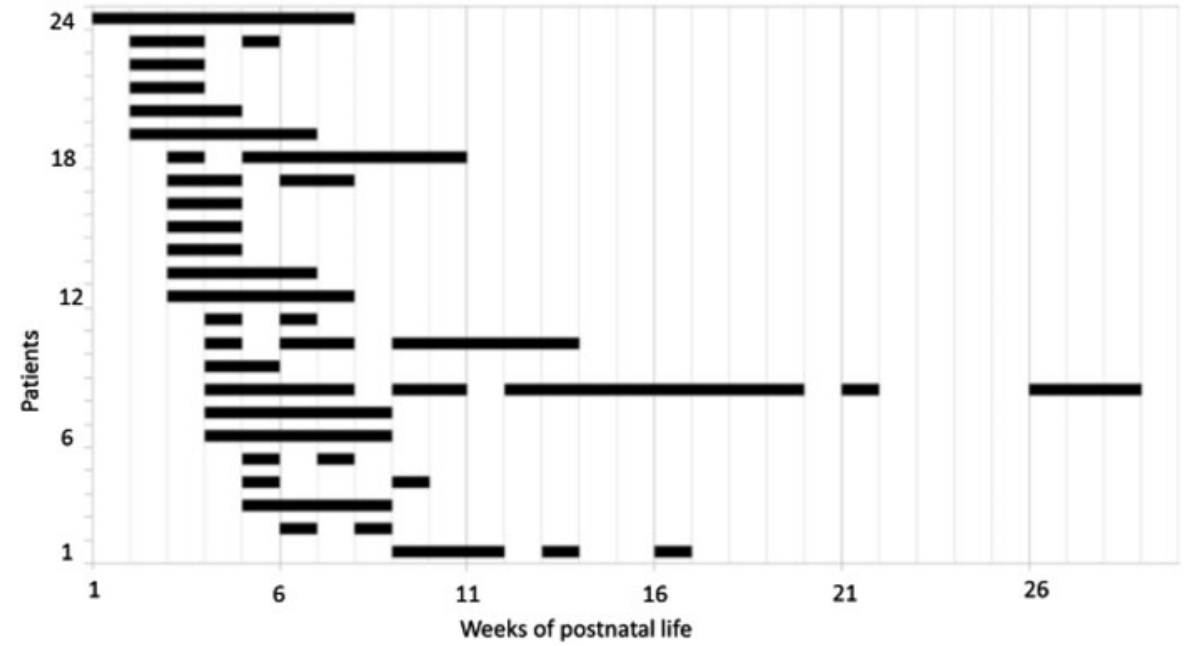

Fig. 1. BM sampling in the multiples' population. Each pair of twins or triplets correspond to a value on the axis of the ordinates (1-24). The sample collection period is reported on the abscissa axis: a solid stretch corresponds to a week in which the sampling has been carried out, while an empty space indicates a nonsampling time. The number on the abscissa axis refers to the not yet completed week of postnatal life (1-29).
Therefore, we evaluated a pool of 54 samples out of the total 103. Obtained data were analyzed according to the dichotomous variables. BM samples from mothers of preterm newborns with GA lower or equal to and higher than 28 weeks were compared ( $\leq 28$ weeks vs. $>28$ weeks). A significant difference $(p=.02)$ was detected in the total protein content (in the lower GA group, protein content resulted greater of a quote equal to $0.1 \mathrm{~g}$ per 100 $\mathrm{ml}$ ); other nutrients did not show significant differences. The mean values for the two groups \pm standard deviation (SD) are reported in Table 3.

In the multiples group, we also evaluated BM composition in relation to the correct GA at the time of analysis (starting from the last maternal menstruation). Out of 103 BM samples, we analyzed only 90 samples collected in the time window between the 30th and the 39th week of correct GA representing a period in which a relatively complete pool of comparable samples was available.

A clear decreasing trend in protein content emerged in relation to the increase in the correct GA $\left(R^{2}=.86\right)$; the decrease was less evident for lipids $\left(R^{2}=.6\right)$ and energy value $\left(R^{2}=.63\right)$. Lactose content did not correlate with GA in our samples.

Our results found some differences in BM from mothers of multiples compared to samples for singletons. Since GA is not homogeneous in the two populations, to allow for a more accurate comparison, we decided to restrict the analysis and evaluated only the samples from mothers of newborns with GA between 24 and 28 weeks. Among the total pool of 24 twins and triplets, only 9 were included in this restricted comparison. In selected samples, nutrient concentrations showed the following mean values: lipids
$3.91 \pm 0.65 \mathrm{~g}$ per $100 \mathrm{ml}$, proteins $1.53 \pm 0.29 \mathrm{~g}$ per $100 \mathrm{ml}$, lactose $6.34 \pm 0.2 \mathrm{~g}$ per $100 \mathrm{ml}$ and energy value $66.68 \pm 6.24 \mathrm{Kcal}$ per $100 \mathrm{ml}$.

The BM intended for singletons showed the following mean values: lipids $3.86 \pm 0.65 \mathrm{~g}$ per $100 \mathrm{ml}$, proteins $1.29 \pm 0.22 \mathrm{~g}$ per $100 \mathrm{ml}$, lactose $6.72 \pm 0.24 \mathrm{~g}$ per $100 \mathrm{ml}$ and energy value $68.87 \pm 6.11 \mathrm{Kcal}$ per $100 \mathrm{ml}$.

Interestingly, the comparison between multiples' and singletons' BM samples showed a statistically significant difference in the total content of proteins and lactose: BM for multiples contained $0.23 \mathrm{~g}$ per $100 \mathrm{ml}$ of extra protein $(p<.01)$ and showed a decrement in lactose content measured as $0.44 \mathrm{~g}$ per $100 \mathrm{ml}$ $(p=.02)$. We report these results in Table 4 .

In addition, we compared the average composition in terms of proteins, lipids, lactose and energy value between $\mathrm{BM}$ for multiples and singletons showing the same GA. The BM from mothers delivering multiples with GA $\leq 28$ weeks was significantly richer in proteins, while lactose concentration was greater in mothers delivering singletons. Conversely, the data on lipids and energy content showed no differences. We report these results in Figure 3.

Finally, we compared the composition of the BM samples, taking into account the following factors: neonatal weight (multiples with at least one neonate showing BW $\leq 1000 \mathrm{~g}$ vs. multiples both weighing $>1000 \mathrm{~g}$ ), intrauterine growth restriction (IUGR) in almost one of the multiples, number of neonates (twins vs. triplets) and neonatal gender (multiples of the same sex vs. discordant sex). However, none of these comparisons provided statistically significant results; therefore, the BM composition was not influenced by such factors. 
Table 3. BM composition according to gestational age ( $\leq 28$ weeks vs. $>28$ weeks)

\begin{tabular}{lccc}
\hline BM characteristics & $\begin{array}{c}\leq 28 \text { weeks of GA } \\
\text { (multiples } n=8 \text { ) }\end{array}$ & $\begin{array}{c}>28 \text { weeks of GA } \\
\text { (multiples } n=15)\end{array}$ & $p$ \\
\hline Lipids $(\mathrm{g} / 100 \mathrm{ml})$ & $4.04 \pm 0.91$ & $3.75 \pm 0.6$ & .42 \\
\hline Proteins $(\mathrm{g} / 100 \mathrm{ml})$ & $1.67 \pm 0.15$ & $1.57 \pm 0.2$ & .02 \\
\hline Lactose $(\mathrm{g} / 100 \mathrm{ml})$ & $6.34 \pm 0.23$ & $6.35 \pm 0.37$ & .68 \\
\hline $\begin{array}{l}\text { Energy value }(\mathrm{Kcal} / \\
100 \mathrm{ml})\end{array}$ & $68.37 \pm 8.41$ & $65.45 \pm 5.71$ & .39 \\
\hline
\end{tabular}

Note: $\mathrm{BM}=$ breast milk, $\mathrm{GA}=$ gestational age.

Results are expressed as mean $\pm S D$.

The $p$ value shown in bold type is significant.
Table 4. Comparison of BM characteristics between multiples and singletons

\begin{tabular}{lccc}
\hline BM characteristics & Multiples $\left(n=9^{\text {a }}\right)$ & Singletons $(n=28)$ & $p$ \\
\hline Lipids $(\mathrm{g} / 100 \mathrm{ml})$ & $3.91 \pm 0.65$ & $3.87 \pm 0.66$ & .71 \\
\hline Proteins $(\mathrm{g} / 100 \mathrm{ml})$ & $1.53 \pm 0.29$ & $1.29 \pm 0.23$ & .00 \\
\hline Lactose $(\mathrm{g} / 100 \mathrm{ml})$ & $6.34 \pm 0.2$ & $6.72 \pm 0.24$ & .02 \\
\hline Energy value $(\mathrm{Kcal} / 100 \mathrm{ml})$ & $66.68 \pm 6.24$ & $66.87 \pm 6.26$ & .96 \\
\hline
\end{tabular}

Note: Since GA $<28$ weeks is an inclusion criteria, 9 twins/triplets and 28 singletons were enrolled. Results are expressed as mean $\pm S D$. Statistically significant results regard proteins and lactose content. The $p$ values shown in bold type are significant.

${ }^{a} 7$ twins and 2 triplets.
(A)

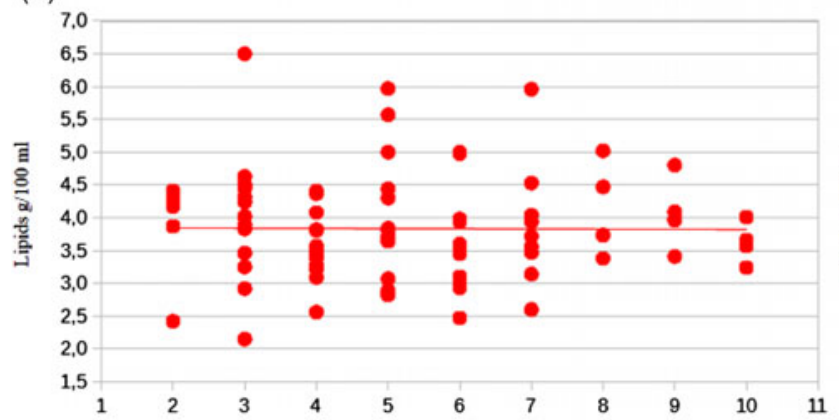

(C)

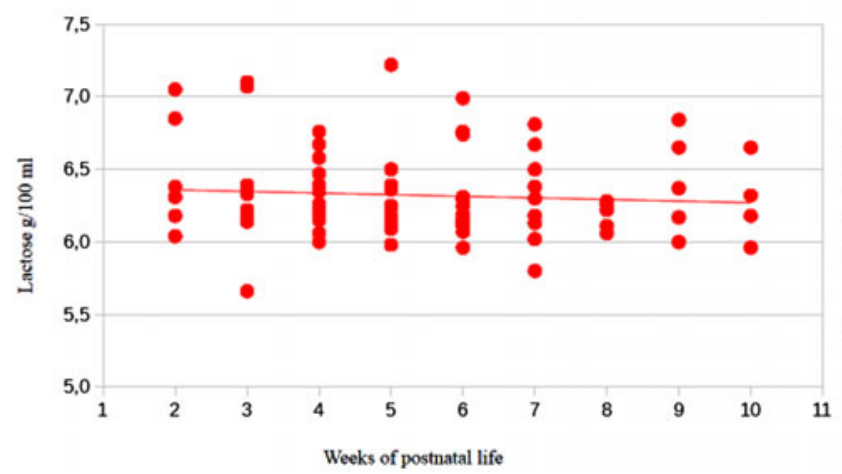

(B)

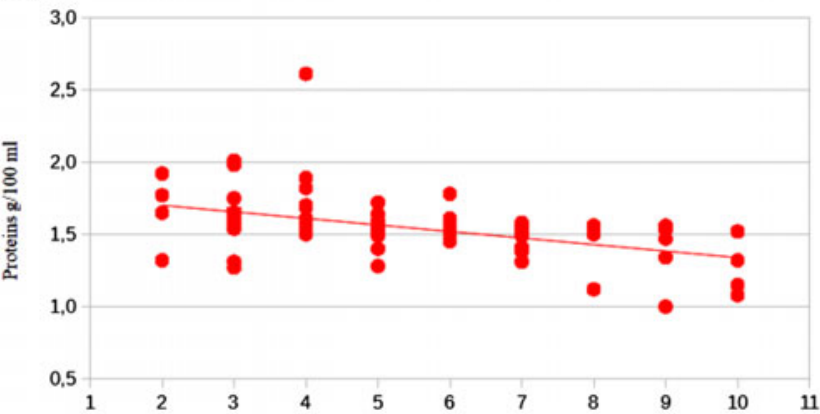

(D)

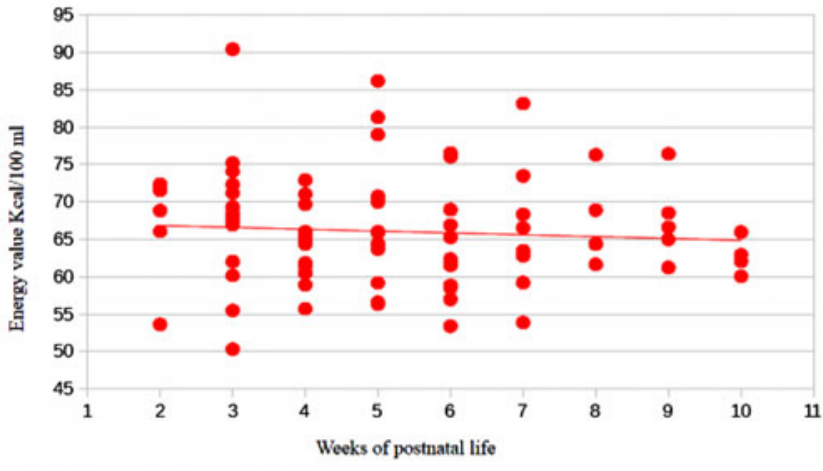

Fig. 2. Weekly variations in lipids (2A), proteins (2B), lactose (2C) and energy value (2D) of multiples' BM. Analysis was performed on the samples collected between the 2 nd and the 10th week of postnatal life. On the abscissa axis the weeks of postnatal life are reported, while on the ordinate axis the quantity of each analyzed components is indicated $(\mathrm{g} / 100 \mathrm{ml}$ or $\mathrm{Kcal} / 100 \mathrm{ml})$. In each image, the trend line is shown. The scale used varies in each image, in proportion to the represented values.

\section{Discussion}

In recent decades, the number of multiple pregnancies has significantly increased in relation to several factors, especially from assisted reproduction techniques. Over $24 \%$ of medically assisted pregnancies are multiples (National Institute for Health and Care Excellence, 2013; SIGO, AOGOI, AGUI Scientific Committees, 2016);multiple pregnancies are complicated by greater perinatal mortality and morbidity than single ones, and GA at delivery is reduced in relation to the number of fetuses (SIGO, AOGOI, AGUI Scientific Committees, 2016).

Although the BM importance in neonatal nutrition is well known, especially in the vulnerable category of preterm newborns, there are still considerable difficulties and controversies in breastfeeding multiples. To the best of our knowledge, this is the first study to investigate $\mathrm{BM}$ composition in mothers of preterm multiples.

The aim of this study was the analysis of macronutrient composition of BM from mothers delivering preterm twins or triplets. We found a nutrient composition comparable to other authors' reports (although they investigated populations of premature singletons), which used similar spectroscopic methods (de Halleux \& Rigo, 2013; McLeod et al., 2016; Reali et al., 2015). We report these results in Table 5.

The analysis of our BM samples, which were collected between the 2 nd and 10 th week of postnatal life, found a temporal variation regarding the concentration of macronutrients. In accordance with the literature on singletons, the results demonstrate a progressive reduction in protein amounts during the first 2 months 
Table 5. Data regarding mean BM composition collected by mothers of preterm newborns, belonging to our analysis or derived from literature review.

\begin{tabular}{|c|c|c|c|c|c|}
\hline & Mean GA (w) & Lipids (g/100 ml) & Proteins $(\mathrm{g} / 100 \mathrm{ml})$ & Lactose $(\mathrm{g} / 100 \mathrm{ml})$ & Energy value $(\mathrm{Kcal} / 100 \mathrm{ml})$ \\
\hline Our data (Singletons $n=28$ ) & $26.29 \pm 1.49$ & $3.87 \pm 0.66$ & $1.29 \pm 0.23$ & $6.72 \pm 0.24$ & $66.87 \pm 6.26$ \\
\hline de Halleux V, 2013 (Singletons $n=24$ ) & $28.6 \pm 1.6$ & $3.79 \pm 0.73$ & $1.52 \pm 0.28$ & $6.76 \pm 0.27$ & $67.3 \pm 6.5$ \\
\hline McLeod G, 2016** (Singletons $\mathrm{n}=20$ ) & $27 \pm 1.9$ & $4.3 \pm 0.7$ & $1.6 \pm 0.5$ & $6.8 \pm 0.7$ & $72.6 \pm 5.9$ \\
\hline
\end{tabular}

$\mathrm{GA}=$ gestational age, $\mathrm{w}=$ weeks, $\mathrm{M}=$ multiples, $\mathrm{S}=$ single birth.

*energy value not reported in the study but calculated according to the quantity of detected nutrients

**Intervention group (individualized fortification)

${ }^{\star \star \star}$ Routine practice group (standard fortification)

(A)

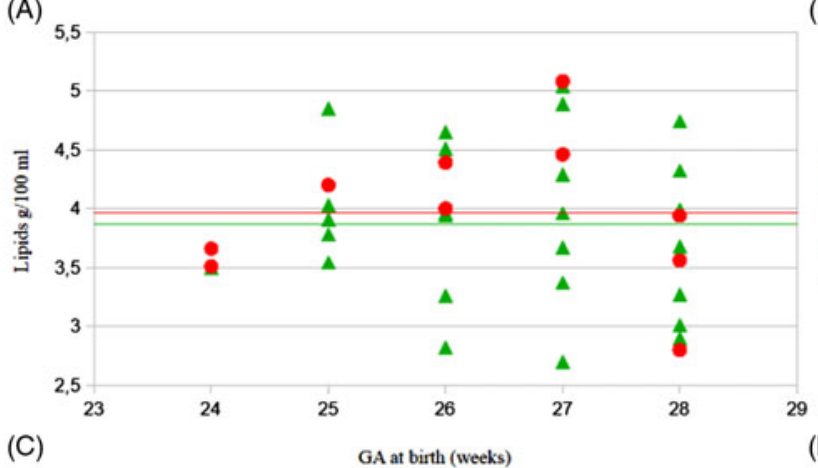

(C)

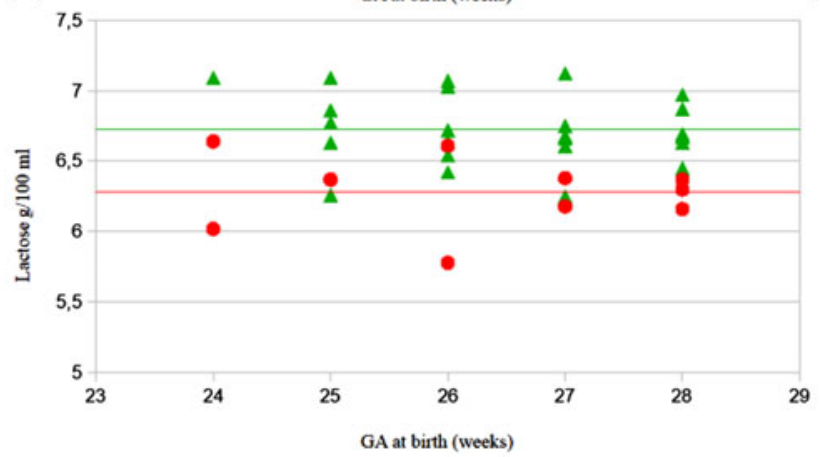

(B)

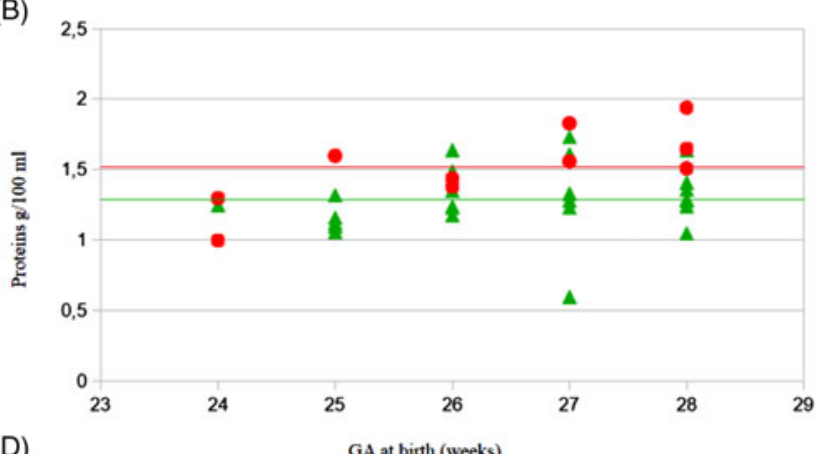

(D)

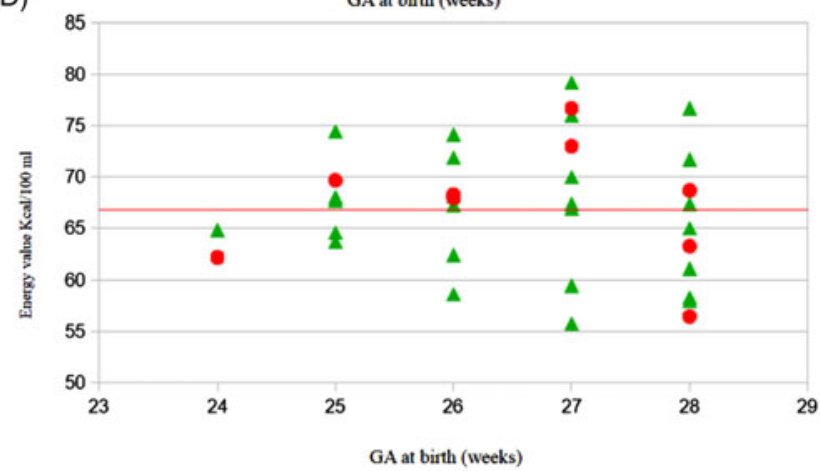

Fig. 3. Comparison between data from multiples' breast milk (BM) and singletons' samples matched for gestational age (GA). Mean values of lipids (3A), proteins (3B), lactose (3C) and energy value (3D) are reported. Each symbol corresponds to a lactating mother whose BM was analyzed; multiples' mothers are marked in red, the singleton's mothers in green. The horizontal line represents the average of the values. On the abscissa axis the week of GA at the time of delivery is reported, while on the axis of the ordinates the quantity of each of the components analyzed is indicated ( $\mathrm{g} / 100 \mathrm{ml}$ or Kcal/100 ml). Used scale is different for each image, correlating to the represented values.

of lactation. This trend represents the key point on which BM fortification is based.

The $84 \mathrm{BM}$ samples collected in the mentioned time window show a negative correlation between weeks of lactation and protein content $(r=-.46)$. However, contrary to what was expected, a temporal variation of other nutrients concentration during lactation did not occur. This could be due to the BM time of collection, since relatively few measurements are available for the lowest corrected GA, despite a higher GA. This could influence the data regarding the lowest and the highest corrected GA.

Moreover, different factors (such as breast squeezing, milk collection at the beginning or the end of the feeding, circadian fluctuations) as well as maternal hormonal changes can affect lipid and lactose composition of BM (Fusch et al., 2015). During BM collection, as per the recommendation of Polberger (2009), we tried to make the samples as homogeneous as possible regarding the collection technique and conditions of sample storage, even if individual maternal variables could have interfered with the analysis. However, we underline that the lipid fraction tends to remain constant over time (despite relative fluctuations). This occurred in our samples and in the meta-analysis reported by Gidrewicz and Fenton (2014) who evaluated BM from mothers of preterm neonates during the first 12 weeks of lactation.

In our study, in agreement with available literature, none of the analyzed factors $(\mathrm{GA}, \mathrm{BW}<1000 \mathrm{~g}$, IUGR, number of multiples and neonatal gender) influenced $\mathrm{BM}$ quantitative composition, except for GA $\leq 28$ weeks. In fact, our data show a statistically significant difference $(p=.02)$ in protein content between multiples with GA $\leq 28$ weeks and $>28$ weeks. GA did not influence other components (lipids, lactose and energy value). Thus, in agreement with the literature regarding singletons, GA was the most relevant factor influencing $\mathrm{BM}$ protein composition: the differences 
regarding protein content in BM of preterm versus full-term neonates and the inverse correlation between protein content and GA have been confirmed (Atkinson et al., 1978; Bauer \& Gerss, 2011).

According to our results, we can confirm that proteins in $\mathrm{BM}$ from multiples decrease during lactation. Moreover, lactose content and energy value show an inverse correlation with the correct GA but not with lactation time, which is influenced more by newborn growth than milk maturation.

In our sample, the most relevant finding was the difference between protein and lactose content in BM from multiples, when compared to singletons' BM, for GA $\leq 28$ weeks. In detail, protein content was higher in multiples' BM (1.53 vs. 1.29 g per $100 \mathrm{ml})$, while lactose concentration was greater in BM from singletons (6.72 vs. $6.34 \mathrm{~g}$ per $100 \mathrm{ml}$ ). Lipid content and caloric value did not significantly differ between the two groups. At the same GA, differences in BM features were comparable; therefore, among the extremely preterm neonates $\leq 28$ weeks, BM for multiples will constantly show more protein and less lactose when compared to $\mathrm{BM}$ for singletons. This could depend on the prolactin (PRL) increase during lactation in mothers of multiples; in fact, they present PRL values up to two times higher than mothers of singletons (Tyson et al., 1976), possibly due to the frequency of newborn meals, which is higher in mothers of twins (Tennekoon et al., 1994).

PRL, in addition to a galactopoietic effect on the mammary gland, stimulates protein production by alveolar cells of mammary epithelium (Healy et al., 1980; Lawrence \& Lawrence, 2016), a mechanism that is potentially increased in twins. Previous studies also demonstrated that mothers of twins produce a double volume of milk, if compared to singletons' mothers (Saint et al., 1986).

In conclusion, we can confirm that multiples fed with BM receive a higher daily protein quantity than singletons. Regarding the lower lactose amount in multiples' BM, this shows an inverse relation to PRL maternal levels (Healy et al., 1980).

Moreover, these findings seem constant at each GA. Thus, for the same GA, BM from multiples tends to be richer in protein and poorer in lactose than BM from mothers of singletons, maintaining this difference throughout the duration of breastfeeding, and therefore during milk maturation.

We can confirm that BM adapts its composition to newborns' needs. It is evident that among all the considered variables, GA is the main influencer of BM composition. This means that preterm neonates receive a higher fraction of proteins, in agreement with the evidence in the literature.

Moreover, our results suggest that such difference decreases with newborn maturation during extrauterine life; each discrepancy disappears if data are analyzed according to the correct $\mathrm{GA}$, suggesting that BM composition in mothers of multiples is similar at a comparable degree of development.

Each of these hypotheses requires further investigations through future studies to evaluate the consequences of higher protein intake on multiples' development, taking into account larger groups of premature neonates, twins and/or multiples and measuring BM content and total volume.

Finally, we cannot exclude the possible influence of maternal genetic factors, which could predispose to a multiple pregnancy, even on the modulation of BM composition. Several studies aim to improve our knowledge of twins and multiples' genetic features, also taking into account the influence of their mothers' pathways, and this could open the way for future studies regarding BM genetic modulation. In this regard, a maternal phenotype has been recently linked to a variable BM content and quality of human milk oligosaccharides, potentially influencing neonatal outcomes (Dessì et al., 2018; Fanos et al., 2018).

Thus, a common genetic influence on multiple pregnancies and $\mathrm{BM}$ content requires further investigation. In our opinion, studies comparing BM variations in samples collected by the same mother but during different pregnancies (ideally in mothers delivering multiples but also singletons in the course of their life) could help in elucidating the role of multiple pregnancy, rather than genetic factors, on BM modulation.

However, this kind of study could show a difficult reliability, both taking into account maternal adherence to the study design during her life and even considering different ages of sample collection, depending on the time of pregnancy occurrence.

\section{Conclusion}

In the literature, reports attesting BM variations during lactation are already available (Gidrewicz \& Fenton, 2014). With our study, we can extend this statement also to BM collected from mothers of multiples, since we detected modifications in its composition during milk maturation, especially regarding a decrease in protein content over time.

In addition, BM for extremely preterm multiples shows a significantly higher protein concentration if compared with samples collected by mothers of multiples with higher GA (Bauer \& Gerss, 2011).

The BM of mothers of multiples contains greater quantities of proteins and lower levels of lactose than samples collected from mothers of singletons. According to our findings, this characterizes the samples collected from newborns with the same GA and is detectable during the whole period.

Such results represent the first evidence in the field of breastfeeding of preterm multiples, a topic not yet clarified and scarcely investigated. However, our findings require further investigation on larger samples (also taking into account different BM composition in the same mother delivering multiples or singletons), integration with genetic studies and, eventually, future confirmation.

Enriching our knowledge on breastfeeding of preterm multiples could help in neonatal nutrition and optimization of fortification strategies, potentially improving short- and long-term neonatal outcome.

Acknowledgments. Some results obtained from this study have been included among the Selected Abstracts of the 20th National Congress of the Italian Society of Perinatal Medicine (Societá Italiana di Medicina Perinatale, SIMP); Catania (Italy); March 22-24, 2018; Session 'Perinatal Miscellanea' (Congiu et al., 2018).

Availability of data and material. The datasets used and/or analyzed during the current study are available from the corresponding author on reasonable request.

Authors' contributions. MC, FB and AR analyzed and interpreted the patient data regarding $\mathrm{BM}$ composition. FD performed $\mathrm{BM}$ analysis. $\mathrm{AD}$ and $\mathrm{VF}$ were major contributors in writing the manuscript. All authors read and approved the final manuscript.

Financial support. The authors declare that this research received no specific grant from any funding agency, commercial or not-for-profit sectors.

\section{Conflict of interest. None.}

Ethical standards. The analysis of BM samples showed in this paper was included in an ongoing individualized fortification program performed in 
our NICU, with the aim to optimize the samples destined to each neonate according to its peculiar needs. Therefore, it does not result an experimental study but a welfare protocol, in which BM analysis is performed to adapt its composition, often inadequate for preterm newborns.

\section{References}

American College of Obstetricians and Gynaecologists. (2016). Practice Bulletin $\mathrm{N}^{\circ}$. 169 Multifetal gestations: Twin, triplet and higher-order multifetal pregnancies. Obstetrics and Gynecology, 128, e131-e146.

Andreas, N. J., Kampmann, B., \& Mehring le-Doare, K. (2015). Human breast milk: A review on its composition and bioactivity. Early Human Development, 91, 629-635.

Atkinson, S. A., Bryan, M. H., \& Anderson, G. H. (1978). Human milk: Difference in nitrogen concentration in milk from mothers of term and premature infants. The Journal of Pediatrics, 93, 67-69.

Ballard, O., \& Morrow, A. L. (2013). Human milk composition: Nutrients and bioactive factors. Pediatric Clinics of North America, 60, 49-74.

Bardanzellu, F., Fanos, V., \& Reali, A. (2017). 'Omics' in human colostrum and mature milk: Looking to old data with new eyes. Nutrients, 9, E843.

Bauer, J., \& Gerss, J. (2011). Longitudinal analysis of macronutrients and minerals in human milk produced by mothers of preterm infants. Clinical Nutrition, 30, 215-220.

Collins, A., \& Shennan, A. (2016). A clinical opinion on how to manage the risk of preterm birth in twins based on literature review. Journal of Maternal Fetal and Neonatal Medicine, 29, 1125-1123.

Congiu, M., Reali, A., Dessì, A., Pintus, R., Puddu, M., \& Fanos, V. (2018). Breast milk for twins: More proteins, less lactose. Journal of Pediatric and Neonatal Individualized Medicine, 7, e070129

de Halleux, V., \& Rigo, J. (2013). Variability in human milk composition: Benefit of individualized fortification in very low birth weight infants. The American Journal of Clinical Nutrition, 98, 529S-535S.

Dessì, A., Briana, D., Corbu, S., Gavrili, S., Cesare Marincola, F., Georgantzi, S., ... Malamitsi-Puchner, A. (2018). Metabolomics of breast milk: The importance of phenotypes. Metabolites, 8, E79.

ESPGAN Committee on Nutrition. (1982). Guidelines on infant nutrition: Recommendations for infant feeding. Acta Paediatrica Scandinavica Supplement, 302, 1-27.

Fanos, V., Reali, A., Marcialis, M. A., \& Bardanzellu, F. (2018). What you have to know about human milk oligosaccharides. Journal of Pediatric and Neonatal Individualized Medicine, 7, e070137.

Fusch, G., Mitra, S., Rochow, N., \& Fusch, C. (2015). Target fortification of breast milk: Levels of fat, protein or lactose are not related. Acta Paediatrica, 104, 38-42.
Gidrewicz, D. A., \& Fenton, T. R. (2014). A systematic review and metaanalysis of the nutrient content of preterm and term breast milk. $B M C$ Pediatrics, 14, 216-229.

Healy, D. L., Rattigan, S., Hartmann, P. E., Herington, A. C., \& Burger, H. G. (1980). Prolactin in human milk: Correlation with lactose, total protein, and alpha-lactalbumin levels. The American Journal of Physiology, 238, e83-e86.

Lawrence, R. A., \& Lawrence, R. M. (2016). Breastfeeding: A guide for the medical profession (8th ed.) St Louis, MO: Elsevier.

Machin, G. (2009). Non-identical monozygotic twins, intermediate twin types, zygosity testing, and the non-random nature of monozygotic twinning: A review. American Journal of Medical Genetics. Part C, Seminars in Medical Genetics, 151C, 110-127.

Martin, J. A., Hamilton, B. E., Ventura, S. J., Osterman, M. J., Kirmeyer, S., Mathews, T. J., Wilson, E. C. (2011). Births: Final data for 2009. National Vital Statistics Report, 60, 1-70.

McLeod, G., Sherriff, J., Hartmann, P. E., Nathan, E., Geddes, D., \& Simmer, K. (2016). Comparing different methods of human breast milk fortification using measured v. assumed macronutrient composition to target reference growth: A randomised controlled trial. The British Journal of Nutrition, $115,431-439$.

National Institute for Health and Care Excellence (NICE). (2013). Multiple pregnancy: Twin and triplet pregnancies. London, UK: Author.

Polberger, S. (2009). New approaches to optimizing early diets. Nestle Nutrition Workshop Series Paediatric Programme, 63, 195-204.

Reali, A., Greco, F., Fanaro, S., Atzei, A., Puddu, M., Moi, M., ... Fanos, V. (2010). Fortification of maternal milk for very low birth weight (VLBW) pre-term neonates. Early Human Development, 86, 33-36.

Reali, A., Greco, F., Marongiu, G., Deidda, F., Atzeni, S., Campus, R., ... Fanos, V. (2015). Individualized fortification of breast milk in 41 extremely low birth weight (ELBW) preterm infants. Clinica Chimica Acta, 451, 107-110.

Saint, L., Maggiore, P., \& Hartmann, P. E. (1986). Yield and nutrient content of milk in eight women breastfeeding twins and one woman breastfeeding triplets. The British Journal of Nutrition, 56, 49-58.

SIGO, AOGOI, AGUI Scientific Committees. (2016). Multiple pregnancy management. Milan, Italy: Confalonieri Ragonese Foundation.

Su, B. H. (2014). Optimizing nutrition in preterm infants. Pediatrics and Neonatology, 55, 5-13.

Tennekoon, K. H., Arulambalam, P. D., Karunanayake, E. H., \& Seneviratne, H. S. (1994). Prolactin response to suckling in a group of fully breast feeding women during the early postpartum period. Asia-Oceania Journal of Obstetrics and Gynaecology, 20, 311-319.

Tyson, J. E., Freedman, R. S., Perez, A., Zacur, H. A., \& Zanartu, J. (1976). Significance of the secretion of human prolactin and gonadotropin for puerperal lactational infertility. CIBA Foundation Symposium, 45, 49-71. 